$\infty$

0

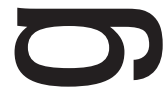

-

ת

1

$\longrightarrow$ 


\title{
RPPN, ECO TURISMO, POPULAÇÕES TRADICIONAIS E/OU RESIDENTES: DILEMAS DE UMA POLÍTICA DE ÁREAS PARTICULARES PROTEGIDAS ${ }^{1}$
}

\author{
RPPN, ECOTURISMO, POBLACIONES TRADICIONALES Y/O RESIDENTES: \\ DILEMAS DE UNA POLÍTICA DE ÁREAS PARTICULARES PROTEGIDAS
}

\author{
Isis Maria Cunha Lustosa - UFG \\ isislustosa@uol.com.br
}

\begin{abstract}
Resumo
0 artigo versa sobre a (UC) Unidade de Conservação - (RPPN) Reserva Particular do Patrimônio Natural e 0 Ecoturismo como elementos de discussão - se há por parte da legislação de áreas protegidas particulares 0 compromisso do reconhecimento das populações tradicionais e/ou residentes, bem como da efetiva participação destas na conservação da natureza em RPPN tomando-se como base artigos do Decreto $\mathrm{n}^{0}$ 1922/05.06.1996 e da Lei $n^{0}$ 9.985/18.07.2000 do (SNUC) Sistema Nacional de Unidades de Conservação, o qual, insere a RPPN como área protegida oficial de propriedade particular reconhecida pelo (IBAMA) Instituto Brasileiro de Recursos Naturais Renováveis, em âmbito federal, ou por órgãos estaduais do meio ambiente. Essa área é reconhecida total ou parcial por decisão do proprietário, permanece na sua posse e domínio com gravame de perpetuidade. 0 IBAMA considera que a RPPN proteja os recursos ambientais pela relevância da sua biodiversidade, pelo aspecto paisagístico ou por características ambientais que justifiquem sua recuperação, concebendo-a atividades que julgam não interferir negativamente na biodiversidade - a educação ambiental, os projetos científicos e 0 turismo ecológico. Ou: a RPPN é mais um espaço emergente em prol da turistificação de área protegida criada na ideologia do ecoturismo?
\end{abstract}

Palavras-chave: RPPN, ecoturismo, conservação, turistificação, população.

\section{Resumen}

El artículo trata sobre la Unidad de Conservación denominada (RPPN) Reserva Particular de Patrimonio Natural y Ecoturismo. Se toma la legislación de áreas protegidas particulares que da reconocimiento a las poblaciones tradicionales y/o residentes y su efectiva participación en la conservación de la naturaleza en la categoría de RPPN, tomando como base los artículos del Decreto $n^{0}$ 1922/05.06.1996 y de la ley $n^{0} 9.985 / 18.07 .2000$ del (SNUC) Sistema Nacional de Unidades de Conservación, el cual inserta a la RPPN como área protegida oficial de propiedad particular reconocida por el (IBAMA) Instituto Brasilero de Recursos Naturales Renovables, en el ámbito federal, o por órganos estaduales del medio ambiente. El área en mención es reconocida total o parcialmente por decisión del propietario, permanece en su pose y dominio con gravamen de perpetuidad. En el artículo se discute si el IBAMA considera que la RPPN protege los recursos ambientales por la relevancia de su biodiversidad, por el aspecto paisajístico o por características ambientales que justifiquen su recuperación, concibiendo las actividades que juzgan no interferir negativamente en la biodiversidad, la educación ambiental, los proyectos científicos y el turismo ecológico. 0 si la RPPN es más un espacio que emerge en pro de la turistificación del área protegida creada en la ideología del ecoturismo.

Palabras claves: RPPN, ecoturismo, conservación, turistificación, población. 


\section{Um primeiro olhar sobre a RPPN}

Ecoa, mundialmente, que as áreas protegidas são um dos instrumentos mais justificados para a conservação da natureza. O Brasil, apesar de ser uma das referências em biodiversidade e destacar-se segundo a (IUCN) União Mundial pela Natureza como um dos quatro países potenciais em diversidades de flora e fauna, ainda assim está aquém da proteção quantiqualitativa dessas espécies biológicas.

O Brasil, enquanto governo, tem procurado se alinhar com as estratégias mundiais de conservação da biosfera por meio do planejamento ambiental e do zoneamento ecológico - o que não tem impedido abusos criminosos dos que estão acima da lei. (YAZIGI, 2001, p. 80)

Baseado no exposto o início do século XXI está calcado por um processo de transição no movimento ambiental moldando-se às novas formas e conteúdos globais. Os diversos sujeitos sociais, seguidores dessa trajetória, clamam para influenciar leis que dêem relevância às temáticas sócio-ambientais.

Nessa perspectiva, o Brasil justifica aprimorar seu novo capítulo ambiental - a exemplo a Lei $\mathrm{n}^{0}$ 9.985/18.07.20000, institui dentro da Política Nacional do Meio Ambiente o (SNUC) Sistema Nacional de Unidades de Conservação da Natureza. Esse sistema integra as (UCs) Unidades de Conservação e dentre as de Uso Sustentável inclui - a RPPN ${ }^{2}$. Conforme preconiza o artigo $7^{\circ}$, II, $\S 2^{\circ}$ dessa lei: “O objetivo básico das Unidades de Uso Sustentável é compatibilizar a conservação da natureza ${ }^{3} \mathrm{com}_{\text {o }}$ uso sustentável ${ }^{4}$ de parcela de seus recursos naturais.” (Rocco, 2002, p. 170).

O SNUC perante a sua legislação insere a RPPN como área protegida oficial de propriedade particular reconhecida pelo (IBAMA) Instituto Brasileiro de Recursos Naturais Renováveis, em âmbito federal, ou por órgãos estaduais de meio ambiente. Essa área é reconhecida total ou parcial por decisão do proprietário, permanece na sua posse e domínio com gravame de perpetuidade e está concessiva de incentivos.

Consideramos que a RPPN está calcada por um passado histórico de antecedentes legais desde os Códigos Florestais brasileiros de 1934 e 1965. No entanto, o seu real reconhecimento ocorreu em 1990 e a revela, hoje, como uma classificação de reserva adolescente - com 14 anos e, pautada por novas discussões no cenário ambiental brasileiro. Contudo, pronunciar ou ouvir a sigla RPPN em nosso país ainda provoca nos sujeitos sociais envolvidos ou 
não com a temática ambiental uma expressão de estranhamento por vezes exacerbada pelo pouco ou nenhum conhecimento sobre área particular.

O Poder Público, representado pelo IBAMA - Instituição representante da legislação da RPPN considera que esta área proteja os recursos ambientais pela relevância da sua biodiversidade, pelo aspecto paisagístico ou por características ambientais que justifique sua recuperação, concebendo-a atividades que julgam "não interferir" negativamente na biodiversidade - a educação ambiental, os projetos científicos e o turismo ecológico.

Para o avanço de nossa discussão antes de definirmos quais dessas atividades mais se integra ao objeto de estudo RPPN é imprescindível mencionarmos logo sobre a biodiversidade. Existem inúmeras incertezas, controvérsias e desconhecimento no tocante a mesma. Por essas más interpretações quase tudo o que se vincula a ela como a própria RPPN gera um sinônimo de perfeição no trato com a conservação da natureza. Mas, se acompanharmos o raciocínio de Almeida (2003) abrimos a cortina que obscurece a biodiversidade. Para essa autora:

\begin{abstract}
A biodiversidade é uma invenção discursiva recente, resultante de uma situação concreta face à crescente destruição da natureza e à perda da diversidade ecológica. Esta preocupação com a natureza coloca em debate a sua instrumentalização e uma reconsideração da construção simbólica da mesma. O discurso sobre a biodiversidade camufla a forma moderna do capital com (re)significação [...] é sobretudo a instituição de uma cultura de conservação que se revela como uma nova interface entre a natureza, o capital e a ciência.
\end{abstract}

Castells (1999, p. 22) já revelava essa obcuridade da biodiversidade. Para ele, "[...] A consciência ambiental permeou as instituições da sociedade e seus valores ganharam apelo político e preço de serem refutados e manipulados na prática diária das empresas e burocracias."

Transferindo essa análise para a nossa discussão de RPPN, coincidentemente os artigos 11, 12 e $13^{5}$ do Decreto $\mathrm{n}^{0}$ 1.922/05.06.1996 atualizador dessa área traduziram-se, respectivamente em incentivos - isenção do (ITR) Imposto Territorial Rural; concessão de recursos do (FNMA) Fundo Nacional do Meio Ambiente e de crédito agrícola pelas instituições oficiais de crédito. "Ora, nesses termos o espaço é estratégico [...] nisso está o conflito, a insurgência do uso." (SEABRA, 1996, p. 79). Os incentivos em vez de servirem para favorecer a conservação da biodiversidade, se sobrepõem a esta? Segundo Santos (2002, p. 239) "os espaços assim [...] atendem sobretudo aos interesses dos atores hegemônicos da economia [...] e da política e são incorporados plenamente às novas correntes mundiais." 
Todavia, o IBAMA é contrário as leituras interpretativas de Almeida; Santos; Castells e Seabra. Esse Instituto assume e expõe que para qualquer um dos biomas do território brasileiro a RPPN representa o passo inicial para interagir a sociedade civil através dos proprietários particulares e alcançar áreas protegidas com qualidade e quantidades significativas.

O IBAMA, também justifica que as áreas protegidas particulares podem ser intensificadas pelas diversas atividades permitidas em seu interior - a educação ambiental, os projetos científicos e o turismo ecológico. Dentre essas, a legislação da RPPN enfatiza a turística - o que nos chama à atenção para (re)pensar essa UC diante do ecoturismo e das ambigüidades de ser - classificada como unidade de conservação da natureza, e não incluir nessa natureza as populações tradicionais e / ou residentes. A população humana da RPPN se restringe ao proprietário? "Tem-se, portanto como imprescindível um primeiro olhar capaz de perceber algo que um transuente comum ou um visitante qualquer não vê.” (MAIA, 1997, p. 27).

\section{Um olhar reflexivo sobre o ecoturismo}

Sabendo que a RPPN enfatiza a área turística em sua legislação. Vale salientar que o setor terciário envolve o comércio e os serviços e, que o turismo insere-se nesse setor. O terciário impulsionou-se com relevância, direcionado pelas tendências hegemônicas globalizadas e, o ecoturismo destinou-se a esta trajetória. Para Rodrigues (2000, p. 87-88) “[...] as atividades de lazer e de turismo vêm assumindo uma importância cada vez mais destacada, sendo consideradas, hoje, os setores que mais crescem no mundo e que mais mobilizam recursos [...] produzindo novos espaços turísticos [...].” Podemos considerar a RPPN como um dos novos espaços em prol do ecoturismo?

Recordamos os Códigos Florestais de 1934 e 1965 “[...] a existência de propriedades particulares destinadas à conservação ambiental já existia expressamente desde o antigo Código Florestal de 19346." (www.ibama.gov.br). Todavia, somente com o advento da nova Lei Florestal $n^{0}$ 4.771/15.09.1965 é que a RPPN veio regulamentar o artigo sexto 7 do Código Florestal/1965 “[...] este artigo, até 1990, nunca tinha sido regulamentado permanecendo "inerte” dentro da Lei Florestal.” (Id., Ibid.). Até essa regulamentação se concretizar houve um longo intervalo entre os anos de 1965 a 1990 para que áreas particulares fossem reconhecidas como RPPN. 
Isso nos leva a questionar: Por que um período de hibernação tão longo para que a RPPN fosse reconhecida? Por que reconhecê-la só nos anos de 1990? Observamos que nesse intervalo de 25 anos até ocorrer o reconhecimento da RPPN pelo Decreto $n^{0}$ 98.914/30.01.1990 tudo girava a favor dos espaços opacos - as áreas particulares até 1989 por não serem reconhecidas estavam aquém dos interesses público, privado e do capital internacional. Entretanto, dois pilares frutos da década de 1990 - a ECO-92 e a atividade turística metamorfosearam os espaços até então opacos em espaços luminosos. "Isto porque em cada momento as sociedades humanas são palco do embate entre as tendências conservadoras e as inovadoras [...]." (LARAIA, 1996, p. 101). Para Faria \& Santiago (2002, p. 76):

A partir de 1992, observa-se que a dimensão ambiental ganha enorme representatividade no processo de globalização e passa a exercer significativa influência no direcionamento das políticas ambientais no âmbito mundial e nacional, dando início a uma fase, que reflete de forma direta na atividade turística. A ECO-92 resgata o interesse pelo “turismo ecológico”, já praticado por um número significativo de pessoas, e recebe uma grande influência ambientalista incorporando princípios conservacionistas em seu conceito, sob a nova designação de "Ecoturismo".

Resgatando o Decreto n ${ }^{0}$ 1.922/ 05.06.1996. Este no seu art. 3 expressou que "as RPPNs poderão ser utilizadas para [...] atividades de cunho científico, cultural, educacional, recreativo e de lazer." Nas atividades de lazer, o turismo, está contemplado. Para Coriolano (1998, p. 115) "o lazer transformado em turismo passa a ser vendido de forma bastante lucrativa, com rápida acumulação e reprodução de capital. Selecionam-se áreas turísticas, alocam-se recursos, definem-se políticas e, sobretudo cria-se a ideologia do turismo - "ecoturismo".

Existem variadas concepções e imprecisões sobre o turismo. "Muitas das vezes fulanos e sicranos nominam seus projetos como ecológicos ao se servirem, por exemplo, de meras maquiagens [...].” (YAZIGI, 2001, p. 84). Estas perpassam pela literatura e pela "autarquia responsável [na] organização do setor turístico no Brasil [...] ou pelos formadores do trade" (SERRANO, op. cit., p. 17). Tanto que "o ecoturismo passa a ser visto como uma alternativa para regiões economicamente fragilizadas, por conter em seu conceito os princípios ambientalistas que venham a promover o desenvolvimento sustentável.” (Faria \& SANTiago, op. cit., p. 76).

Nesses termos tanto há quem considere ou discorde do ecoturismo como beneficiador econômico regional e nacional. Seabra (Op. cit., p. 74) 
constata "no processo de desenvolvimento da forma de mercadoria, tanto os elementos de ordem material existente no mundo, como terra, ar, água, entram no processo de valorização, quanto o próprio homem [...].” Fato que requer um olhar vigilante, pois "saber olhar é imprescindível [...]. Evidentemente que este olhar também precisa ser renovado, mas antes de tudo aguçado. Olhar que se difere do olhar descomprometido de um turista comum." (MAIA, op. cit., p. 27). O olhar aguçado se manifesta com a finalidade de evitar uma visão simplista e equivocada que se traduz numa concepção vaga sem avaliar as atividades resultantes do desenvolvimento do ecoturismo.

Mesmo assim, há os que se apoderam da 'visão simplista '. Com isso a prática do ecoturismo como beneficiador econômico faz com que seus índices $^{8}$ ascendam em escala mundial. Segundo Costa (2003, p. 40) "aos poucos, o Governo começa a perceber o grande filão do turismo em áreas naturais”. Acreditamos que o turismo pensado somente como 'filão' é apoderado pela vertente econômica e desagrega-se das demais - a social, a cultural, a ecológica, a política e a espacial. Compreendemos que nenhuma vertente deve ser abolida em prol da outra. Mas, se interagirem para compor "o fenômeno no seu universo complexo, polissêmico e multifacetado.” (RoDRIGUEs, 2000, p. 88).

É preciso perceber que existem critérios a serem direcionados à prática de qualquer tipo de turismo. Segundo Coriolano (2000, p. 2), “o ecoturismo apresenta-se carregado de ideologias e intenções que precisam ser identificadas [...]." Para ela "o ecoturismo resurge como uma atividade econômica do mundo moderno, que pode degradar, mas também pode ser uma forma de conservação ambiental, depende [do modo] que for implementado." (Op. cit., p. 11). A autora enfatiza:

O ecoturismo é uma forma de valorizar o patrimônio natural, histórico, cultural e a participação das comunidades locais. É o turismo motivado pela valorização ambiental e pela descoberta da natureza como valor estético transformado em ativo ambiental. (Id., Ibid., p. 11)

Todavia, a concepção de desenvolvimento do ecoturismo como forma de conservação ambiental muitas vezes não ultrapassa o discurso dos sujeitos sociais interessados na iluminar novos espaços em prol do capital. Luchiari (2000, p. 36) constata:

O fenômeno turístico [...] mitifica a realidade dando-lhe novos conteúdos. Força o traço dos lugares, das regiões, das paisagens criando atrativos para o fluxo da sociedade. O todo significante desta criação não está nos lugares, nas regiões, 
ou nas paisagens. Estrutura-se na sociedade que, ao revalorizar as paisagens naturais, as culturas regionais, transforma-se em voraz consumidora, colocando em movimento a construção real e simbólica dos territórios turísticos.

Assim, Rodrigues reforça que "os efeitos do turismo [...] demandam urgência e seriedade científica nas pesquisas, particularmente nos países [...] localizados no mundo intertropical, com [...] reservas naturais quantitativamente e qualitativamente reconhecidas como patrimônio [...]" (Op. cit., p. 99). Isso provoca-nos uma (re)interpretação sobre o reconhecimento da RPPN e a prática da atividade ecoturística. Visto que o compromisso dos sujeitos sociais (poder público e proprietário) com essas reservas particulares - se mantêm dúbio entre: a conservação da natureza e a turistificação.

Para Almeida (1999, p. 20), "a turistificação é o processo de apropriação do lugar para e pelo turismo”. Essa autora considera que os espaços se artificializam ou se turistificam no momento em que são destinados para as satisfações dos que chegam de fora. Frente a uma preocupação maior com a proteção da natureza, versa um interesse mais mercadológico do que ambiental. Almeida diz ainda: "o olhar extasiado confunde-se com o olhar valorativo.” (Id., 2000, p. 55). Vemos a oportunidade da turistificação quando Costa (Op. cit., p. 40) diz:

As Reservas Particulares do Patrimônio Natural [...] são [...] as categorias de Unidades de Conservação mais importantes para o incremento do turismo, em seu segmento ecoturismo [e] as RPPNs são particulares, o que requer e depende de interesses privados para o desenvolvimento turístico nessas áreas.

Portanto, Almeida considera que “[...] no contexto atual, a valorização dos aspectos econômicos do turismo tem negligenciado os estudos e a condição dos aspectos relacionados à natureza, a cultura e aos aspectos psicossociais [...]" (2000, p. 60). Fato que repercute diretamente sobre as populações tradicionais e / ou residentes. Hoje com a classificação RPPN faz-se diferente?

\section{Contradições da RPPN: populações tradicionais e/ou residentes?}

Partimos da interrogação e acompanhamos alguns pontos-chaves da Lei $n^{\circ}$ 9.985/18.7.2000, que institui o SNUC, nessa há menção sobre as populações tradicionais. O seu cap. II, artigo $4^{\circ}$, XIII (RocCO, 2000, p. 168) diz "[deve-se] proteger os recursos naturais necessários à subsistência de 
populações tradicionais, respeitando e valorizando seu conhecimento e sua cultura e promovendo-as social e economicamente."

No entanto, o Decreto $\mathrm{n}^{\mathrm{o}}$ 1.922/05.06.1996, o qual foi considerado atualizador da RPPN dispôs sobre o reconhecimento desta área e, nada explicitou sobre as populações tradicionais ou residentes. O seu artigo $3^{\circ}$, $1^{\mathrm{o}}$, mencionou que "As atividades previstas nesse artigo deveriam ser [...] executadas de modo a não comprometer o equilíbrio ecológico ou colocar em perigo a sobrevivência das populações das espécies ali existentes [...]." (Id., Ibid, p. 196, grifo nosso). Esse é o único artigo que comenta sobre populações. O IBAMA entende essas populações somente como fauna e flora? Por que esse Instituto inclui o proprietário como população humana da RPPN e nada explicita sobre uma possível população humana tradicional ou residente nessa área? Segundo Ganem \& Leal (2002, p. 65):

Estão sujeitas ao uso sustentado dos recursos naturais aí existentes e admitem a presença de populações residentes, tradicionais (FLONA, Reserva Extrativista, Reserva de Desenvolvimento Sustentável) ou não tradicionais (APA, ARIE). Excetuam-se apenas a Reserva de Fauna, destinada a exploração de recursos faunísticos, e a RPPN, reserva particular destinada à conservação da diversidade biológica, que admite, ainda assim, a extração de recursos naturais.

A citação anterior nos faz refletir o raciocínio de Gonçalves (2000). De acordo com ele o imaginário racionalista provocou uma fragmentação na relação homem-natureza da relação homem-homem. Praticamente, operacionalizaram-se as relações sociais. Para Diegues (1997, p. 92):

[...] a noção de [...] áreas naturais protegidas que excluam as populações tradicionais é incompreensível [...] A disfunção forçada entre natureza e a cultura tradicional, em que os homens são proibidos pelo Estado de exercer as suas atividades do fazer patrimonial, e também do saber, representa a imposição de um mito moderno: o da natureza intocada e intocável, próprio da sociedade urbano-industrial sobre os mitos das sociedades tradicionais.

Ribeiro \& Barros (1997, p. 41) compartilham do ideário de Diegues e consideram:

Nesse sentido, resta [...] enfrentar o difícil problema da ampla incorporação pelas populações locais dos benefícios gerados por suas atividades, de sua transformação, enfim, em sujeitos do desenvolvimento.

O contexto dessa discussão está permeado por diversas contradições identificadas em literaturas especializadas, nas notícias veiculadas no site 
do IBAMA; na Lei que institui o SNUC e, especialmente, no Decreto que atualizou a RPPN. Identificamos no site do IBAMA (2003) uma referência sobre ecoturismo essencial para fundamentarmos a exclusão causado as populações tradicionais e/ou residentes na legislação da RPPN. Uma das questões realizadas por esse instituto assim foi veiculada:

O QUE É EXATAMENTE O ECOTURISMO? É o "turismo desenvolvido em localidades com potencial ecológico, de forma conservacionista, procurando conciliar a exploração turística com o meio ambiente, harmonizando as ações com a natureza, bem como oferecendo aos turistas um contato íntimo com os recursos naturais e culturais da região, buscando a formação de uma consciência ecológica. O ecoturismo visa igualmente o desenvolvimento das regiões em que se insere, devendo ser um instrumento para a melhoria da qualidade de vida das populações que acolhem essa atividade.” Essa é a definição formulada pela Comissão Técnica Embratur/Ibama. (www.ibama.gov.br, grifo nosso)

Quando nos deparamos com essa definição de ecoturismo inserida no próprio site e link do IBAMA, os quais tratam especificamente de RPPN, e as comparamos com o que foi exposto no Decreto $\mathrm{n}^{\mathrm{0}}$ 1.922/05.06.1996, o qual até a Lei do SNUC perdurou como atualizador e reconhecedor dessas áreas - imaginamos está havendo “[...] mais um monólogo que um diálogo [...] em matéria ambiental” (Leis, 1999, p. 106), no tocante as discussões sobre áreas particulares desse instituto. Tanto que grifamos a expressão populações nas citações anteriores. Segundo Gonçalves (2000, p. 77) "podemos falar de uma população de cadeiras, de uma população de coelhos, de uma população de automóveis [...], etc.”

Por essa diversidade de significados impostos a população - as questões são: Qual classificação de população trata o ecoturismo? Animais? Vegetais? Interpretamos que sejam as humanas. Tradicionais? Residentes? Interrogamos, pois: a RPPN legalmente não trata de população tradicional e/ou residente, mas de "diversidade biológica" (GANEM \& LEAL, 2002, p. 65). Como entender essa exclusão? Se essa área permite a "extração dos recursos naturais” (Id., Ibid., p. 65). Quem os extrai? Que patrimônio cultural o ecoturismo apregoa na RPPN se as populações não são identificadas? Como compreender o ecoturismo na RPPN - se esse depende da cultura e da presença do homem? E esse homem, além do proprietário está obscuro na legislação da RPPN. Segundo Diegues "quando se fala na importância das populações tradicionais na conservação da natureza, está implícito o papel preponderante da cultura e das relações homem/natureza [...].” (1996, p. 75).

Nesse sentido Gonçalves (2000, p. 97) diz: 
Um conceito-chave de toda cultura é o conceito de natureza. Essa afirmação talvez abra uma porta interessante para novas reflexões, libertando-nos da armadilha em que até agora estivemos enredados tentando buscar aquela característica que faria o homem saltar do reino da natureza para o reino da cultura [...] pois como nos diz Serge Moscovici, "tudo nos incita a pôr fim à visão de uma natureza não-humana e de um homem não-natural.

Não finalizamos nossas atuais futuras indagações. Mas, deixamos reflexões que nos estimule a continuar interrogando. Nessa perspectiva, consideramos que "conservar a natureza”, na qual só parte da população humana está presente (proprietário/visitante) e a outra parte está indefinida ou até ausente é um contrasenso aos preceitos da participação cidadã nas reservas particulares protegidas. "Para essas populações é incompreensível que suas atividades [...] sejam consideradas prejudiciais a natureza quando se permite a implantação [...] e facilidades turísticas para usuários de fora da área [...].” (Diegues, op. cit., p. 19).

\section{Considerações finais}

Neste contexto geral de uma pseudo-revalorização da natureza, de reconhecimento de novas RPPNs e de desenvolvimento da atividade ecoturística, ocorre um processo de transformação dos espaços inseridos no mundo globalizado. Estes espaços são metamorfoseados em pontos de reprodução do capital. Para Santos (1992, p. 12) "[...] as atividades terciárias converteram-se na fonte essencial de dominação e acumulação.” Tanto que para (Costa, C., 2002, p. 334) "a instalação de uma unidade de conservação [...] possibilita a inserção do lugar na rede turística [...], ou seja, mercantiliza-se os elementos da natureza [...], pois a rede turística está inserida na atividade terciária.

Essas são algumas poucas questões, certamente, com o nosso olhar empírico. A tendência é de que se esclareçam, persistam ou surjam outras novas interrogações na construção teórica e prática dessa temática. Visto que muitos aspectos ainda estão por esclarecer ou (re)avaliar. Não há como ignorar a RPPN e o ecoturismo. Mas, o que são esses se estiverem desarticulados da natureza, da cultura e dos aspectos psicossociais.

Diante de um quadro de contradições tentamos direcionar uma reflexão que promovesse conceber aspectos mediadores entre a RPPN a prática do ecoturismo. Reflexão essa que deve despertar os elaboradores das políticas 
do meio ambiente; os gestores das Unidades de Conservação e a sociedade a se questionarem quanto a ser a RPPN um espaço luminoso quando esta vem servir ao ecoturismo; e automaticamente um espaço opaco se negar os preceitos ambientais assumidos para a conservação da natureza - como as populações locais. Assim sendo, as políticas ambientais melhor convergiriam para a prática da conservação da natureza e não apenas a turistificação.

\section{Notas}

Artigo desenvolvido e adaptado do Projeto de Pesquisa em andamento do Mestrado em Geografia - IESA/UFG na Área de Concentração: Natureza e a Apropriação do Espaço do Cerrado sob orientação da Profa. Dra. Maria Geralda de Almeida - IESA/UFG.

2 A RPPN no Brasil foi criada pelo Decreto Federal no 98.914 de 30 de janeiro de 1990, e foi atualizado mediante o Decreto $\mathrm{n}^{\circ}$ 1.922, de 5 de junho de 1996 [...] (www.ibama.gov.br).

3 Conservação da natureza: o manejo do uso humano da natureza, compreendendo a preservação, a manutenção, a utilização sustentável, a restauração e a recuperação do ambiente natural, para que se possa produzir o maior benefício, em bases sustentáveis, às atuais gerações, mantendo seu potencial de satisfazer às necessidades e aspirações das gerações futuras, e garantindo a sobrevivência dos seres vivos em geral (Lei $\mathrm{n}^{\circ} 9.985 / 2000$, art. $2^{\circ}$, II) (Rocco, Op. cit., p. 166).

4 Uso sustentável: exploração do ambiente de maneira a garantir perenidade dos recursos ambientais renováveis e dos processos ecológicos, mantendo a biodiversidade e os demais atributos ecológicos, de forma socialmente justa e economicamente viável (Lei $n^{\circ}$ 9.985/2000, art. $2^{\circ}$, II). (Id., Ibid., p. 166).

5 Ver (Rocco, p. 199, 2000).

6 O Código Florestal instituído em 1934, ano em que também ocorre a primeira Conferência Brasileira para a Conservação da Natureza, é que abrirá perspectivas objetivas para o surgimento de UC's mais abrangentes do que as antigas reservas e hortos florestais (SERRANO, 1997, p. 107).

7 A Lei Florestal de 1965 extinguiu a classificação de florestas [protetoras] até então vigente e a única modalidade de gravame em área particular que permaneceu está prevista no artigo $6^{\circ}$ [as floresta não preservadas] (www.ibama.gov.br).

8 [...] estimativas apontam que, em 1994, o ecoturismo representava cerca de $5 \%$ do mercado do turismo no Brasil, sendo responsável por uma movimentação de US\$ 2 bilhões. Estima-se um crescimento de mais de $1 \%$ ao ano, sendo que, para o ano 2005, a projeção é de que o ecoturismo represente cerca de $15 \%$ do mercado turístico, podendo vir a movimentar cerca de US\$10,8 bilhões em nossa economia (FARIa \& SANTIago, 2002, p. 77).

\section{Referências}

ALMEIDA, Maria Geralda. Cultura: invenção e construção do objeto turístico. Espaço aberto3 turismo e formação profissional. Fortaleza: AGB-Seção Fortaleza, 1999. 
. Algumas inquietações sobre ambiente e turismo. In: MENEZES, Ana Virgínia C. de \& $\overline{\mathrm{PINTO}}$, Joseja Eliane S. de Siqueira. Aracaju: NPGEO/UFS, 2000.

. Cultura ecológica e biodiversidade. In: SALES, Vanda Claudino (Org.). Ecossistemas brasileiros: manejo e conservação. Fortaleza: Expressão Gráfica e Editora, 2003.

CASTELLS, Manuel. A sociedade em rede. Tradução: Roneide Venâncio Majer. São Paulo: Paz e Terra, 1999.

CORIOLANO, Luzia Neide M. T. (Org.). Lazer e turismo em busca de uma sociedade sustentável. In: Turismo com ética. Fortaleza: Ed. da UECE, 1998.

. O ecoturismo e os hóspedes da natureza. Palestra proferida no IV Encontro de Turismo com Base Local em Joinville. 2000.

COSTA, Cecília Aparecida. O parque estadual das várzeas do rio ivinhema - MS: produção do território e proteção ambietal. In: SOUZA, Maria José (Org.). Políticas públicas e o lugar do turismo. Brasília: Universidade de Brasília; Departamento de Geografia; Ministério do Meio Ambiente. 2002.

COSTA, Patrícia Côrtes. Unidade de conservação: matéria-prima do ecoturismo. São Paulo: Aleph, 2002.

DIEGUES, Antonio Carlos S. O mito moderno da natureza intocada. São Paulo: Hicitec, 1996.

As áreas naturais protegidas, o turismo e as populações tradicionais. In: SERRANO, Célia M. Toledo \& BRUHNS, Heloísa T. (Orgs.). Viagens à natureza: turismo, cultura e ambiente. Capinas, SP: Papirus, 1997.

FARIA, Ana Lúcia \& SANTIAGO, Alina Gonçalves. Ecoturismo no Brasil: distância entre as políticas públicas e a realidade local. In: SOUZA, Maria José (Org.). Políticas públicas e o lugar do turismo. Brasília: Universidade de Brasília; Departamento de Geografia; Ministério do Meio Ambiente. 2002.

GANEM, Roseli Senna \& LEAL, Zita de Moura. Parques do Distrito Federal: desafios à sua implantação. In: DUARTE, Laura Maria Goulart \& THEODORO, Suzi Huff (Orgs.). Dilemas do cerrado: entre o ecologicamente (in)correto e o socialmente (injusto). Rio de Janeiro: Garamond, 2002.

GONÇALVES, Carlos W.P. Os (des)caminhos do meio ambiente. São Paulo: Contexto, 2000.

IBAMA. 2002. Disponível em: < http://www.ibama.gov.br>. Acesso em: out./nov., 2002. . 2003. Disponível em: <http://www.ibama.gov.br>. Acesso em: jun. 2003.

LARAIA, Roque de Barros. Cultura: um conceito antropológico. Rio de Janeiro: Jorge Zahar Editor, 1996.

LEIS, Héctor Ricardo. A modernidade insustentável: as críticas do ambientalismo à sociedade contemporânea. Petrópolis, Rio de Janeiro: Vozes: Santa Catarina: Ed. da UFSC, 1999.

LIMA, Ricardo Barbosa. Natureza: uma categoria do social. In: DUARTE, Laura Maria Goulart \& BRAGA, Maria Lúcia Santana (Orgs.). Tristes cerrados: sociedade e biodiversidade. Brasília: Paralelo 15, 1998.

LUCHIARI, Maria Teresa D. P. Turismo e meio ambiente na mitificação dos lugares. In: Turismo em análise. São Paulo: [s.n], 2000. 
MAIA, Doralice Sátyro. Os escritos etnográficos e a geografia: encontros e desencontros. Revista Geousp, n. 2. São Paulo, USP, 1997.

RIBEIRO, Gustavo Lins \& BARROS, Flávia Lessa. A corrida por paisagens autênticas: turismo, meio ambiente e subjetividade no mundo contemporâneo. In: SERRANO, Célia M. Toledo \& BRUHNS, Heloísa T. (Orgs.). Viagens à natureza: turismo, cultura e ambiente. Campinas, SP: Papirus Editora, 1997.

ROCCO, Rogério (Org.). Legislação brasileira do meio ambiente. Rio de Janeiro: DP\&A Editora, 2002 .

RODRIGUES, Adyr Balastreri (Org.). Geografia do turismo: novos desafios. In: TRIGO, Luiz Gonzaga Godoi (Org.). Como aprender turismo como ensinar. São Paulo: Editora SENAC, 2000.

SANTOS, Milton. Pensando o espaço do homem. São Paulo: Hucitec, 1992.

. A natureza do espaço: técnica e tempo, razão e emoção. São Paulo: Ed. da USP, 2002.

SEABRA, Ocette Carvalho de Lima. A insurreição do uso. In: MARTINS, José de Souza (Org.). Henri Lefebvre e o retorno à dialética. São Paulo: Hucitec, 1996.

SERRANO, Célia Maria de Toledo. Uma introdução à discussão sobre turismo, cultura e ambiente. In: SERRANO, Célia Maria de Toledo; BRUHNS, Heloísa T. (Orgs.). Viagens à natureza: Turismo, cultura e ambiente. Campinas, SP: Papirus, 1997.

. A vida e os parques: proteção ambiental, turismo e conflitos de legitimidade em unidades de conservação. In: SERRANO, Célia Maria de Toledo; BRUHNS, Heloísa T. (Orgs.). Viagens à natureza: Turismo, cultura e ambiente. Campinas, SP: Papirus, 1997.

YAZIGI, Eduardo. A natureza como identidade espacial do turismo. In: ROSENDAHL, Zeny; CORREA, Roberto Lobato. Religião, identidade e território. Rio de Janeiro: Ed. da Uerj, 2001.

ISIS MARIA CUNHA LUSTOSA - Mestranda em Geografia - IESA/UFG/Bolsista do CNPq.

Recebido para publicação em maio 2005

Aceito para publicação em outubro 2005 